\title{
Axial Coordination of Phosphine or Phosphite to Iron(III) Chlorophyll $a$
}

\author{
Hidenari Inoue, Hiromi Akahori, Yuri Ohno, Katsuo Nakazawa, \\ Yoshimune Nonomura, Naoki Yoshioka, Gernot Heckmannª, \\ Ekkehard Fluck*b \\ Department of Applied Chemistry, Keio University, 3-14-1 Hiyoshi, Kohoku-ku, \\ Yokohama 223 (Japan) \\ a Institut für Anorganische Chemie der Universität Stuttgart, Pfaffenwaldring 55, \\ D-70569 Stuttgart (Germany) \\ b Gmelin-Institut für Anorganische Chemie der Max-Planck-Gesellschaft, \\ Varrentrappstraße 40/42, D-60486 Frankfurt am Main (Germany) \\ Z. Naturforsch. 50b, $1222-1228$ (1995); received February 21, 1995 \\ Iron(III) Chlorophyll $a$, (Phosphine)iron(III) Chlorophyll $a$, (Phosphite)iron(III) \\ Chlorophyll $a$, X-Ray Photoelectron Spectra, NMR Spectra \\ The adduct formation of iron(III) chlorophyll $a$ with phosphines or phosphites has been \\ studied by spectroscopic methods. The red-shift in the Soret and Q bands caused by the axial \\ coordination of phosphine or phosphite to iron(III) chlorophyll $a$ is an evidence for the \\ autoreduction of the central iron(III) ion. The ${ }^{31} \mathrm{P}\left\{{ }^{1} \mathrm{H}\right\}$ NMR spectrum of bis-adducts mea- \\ sured in the presence of excess phosphine or phosphite ligands gave a single peak in the \\ down field range compared to that of the corresponding free ligand. The ESR and X-ray \\ photoelectron spectra have revealed that the central iron atom of the bis-adduct of iron \\ chlorophyll $a$ with phosphines or phosphites is divalent and in the low-spin state. The axial \\ coordination of phosphine or phosphite influences the electronic configuration of the central \\ iron atom and the macrocyclic chlorine ligand to induce the autoreduction of the central \\ iron(III) ion.
}

\section{Introduction}

The redox reaction of metalloporphyrins plays an important role in bioinorganic chemistry of metalloproteins. The axial coordination of nitrogen-containing ligands to iron(III) porphyrins is well-known to give rise to the reduction of highspin iron(III) ion to low-spin iron(II) ion. So far, there has been a wide variety of studies on the socalled autoreduction of metalloporphyrins accompanied by the axial coordination of nitrogen-containing heterocyclic ligands such as pyridine and its derivatives [1-5]. In spite of much interest in iron porphyrins, only a limited number of papers has been published on the autoreduction of the central iron atom in iron(III) chlorophylls [6-7]. The structural characteristics of the macrocyclic chlorine ring in iron(III) chlorophyll $a$ should be closely connected with changes in the electronic state of the central iron ion. Interestingly, Sege and Smith [8] showed, by X-ray crystallographic analysis, that the planarity of the nickel(II) methylpyropheophorbide $a$ is changing due to the

* Reprint requests to Prof. Dr. Dr. h.c. E. Fluck. saturation of one of the four pyrrole rings and the adjacent cyclopentenone ring to give a non-planar system. In the present study the autoreduction induced by the axial coordination of phosphine or phosphite to iron(III) chlorophyll $a$ has been investigated in comparison to that in iron(III) porphyrins in order to clarify the structural feature of the macrocyclic chlorine ring (Fig. 1). Phosphines or phosphites have been selected as axial ligands because the electron-donating and -withdrawing power of the phosphorus ligand is easily tuned by replacing the alkyl or alkoxy groups adjacent to the phosphorus ligand atom. The bis-adducts of iron chlorophyll $a$ with phosphine or phosphite have been characterized in solution and in solid state to learn how the structure of the macrocyclic chlorine ring or the properties of the axial phosphine or phosphite ligands influence the autoreduction behavior of iron(III) chlorophyll $a$.

\section{Experimental}

\section{Materials}

All chemicals commercially available from Kanto Chemical Co. Inc. and Junsei Chemical Co. Ltd. were of reagent grade and used as received 


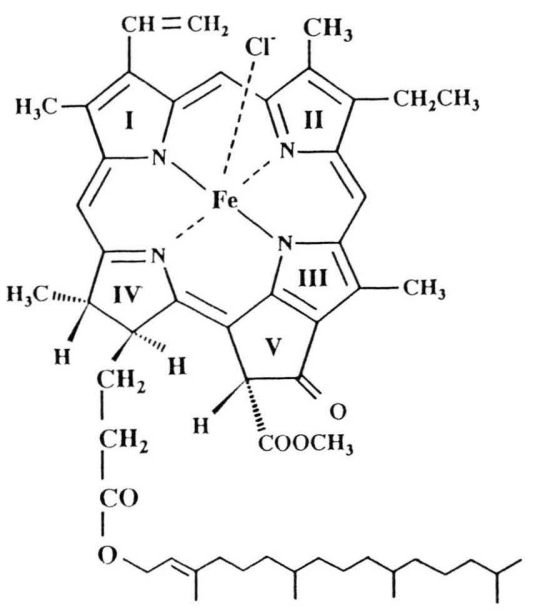

Fig. 1. Structure of iron(III) chlorophyll $a$.

without further purification. All solvents were dried in the usual manner and deoxygenated prior to use with a stream of dry argon. The solvents used for NMR and ESR measurements were obtained from Wako Chemicals Co. and those for electronic spectra were of spectrograde. Iron(III) chlorophyll $a$ was prepared and purified as described previously [9].

\section{Preparation of bis-adducts}

To a solution of $5.0 \mathrm{mg}\left(1.05 \times 10^{-6} \mathrm{~mol}\right)$ iron(III) chlorophyll $a$ in $2.5 \mathrm{ml}$ of chloroform was added $2.63 \times 10^{-6} \mathrm{~mol}$ of trialkylphosphine (or $52.5 \times 10^{-6}$ mol of trialkylphosphite). The reaction mixture was stirred at $30^{\circ} \mathrm{C}$ for $3 \mathrm{~h}$, then cooled to room temperature, and evaporated to dryness to yield the bis-adduct of iron chlorophyll $a$ with phosphine or phosphite. The bis-adducts obtained were subjected to physical measurements in solid state. All operations were performed in the absence of light and in an argon atmosphere.

\section{Instruments}

The electronic absorption spectra were recorded on a JASCO V-550 UV-VIS spectrophotometer using $1 \mathrm{~cm}$ quartz cells. The ${ }^{31} \mathrm{P}\left\{{ }^{1} \mathrm{H}\right\}$ NMR spectra were recorded on $\mathrm{CDCl}_{3}$ solutions of bis-adducts of iron chlorophyll $a$ with phosphine or phosphite on a Bruker WP80 FT NMR spectrometer. The ESR spectra were taken of a frozen chloroform solution of iron chlorophyll $a\left(c a .4 .7 \times 10^{-3} \mathrm{M}\right)$ at $77 \mathrm{~K}$ with a JEOL RE-3X spectrometer. A 100fold excess of the phosphorus ligands $(0.47 \mathrm{M})$ was added to the chloroform solution in the absence of oxygen. Anaerobic samples were prepared by degassing the solvent by three freeze-thaw cycles. The ${ }^{57} \mathrm{Fe}$ Mössbauer spectra were measured against a ${ }^{57} \mathrm{Co}$ source in $\mathrm{Rh}$ foil with a Wissel constant-acceleration transducer coupled to a Canberra OMEGA-1 multichannel analyzer. The sample was cooled to liquid nitrogen temperature $(77 \mathrm{~K})$ in a Torisha cryostat. The ${ }^{57} \mathrm{Fe}$ Mössbauer spectra were fitted to Lorentzian curves using a least-squares iterative computer program. The isomer shift was referred to the centroid of the sextet of natural iron foil kept at $20^{\circ} \mathrm{C}$. The X-ray photoelectron spectra were taken at room temperature with a JEOL JPS-90SX spectrometer using $\mathrm{MgK}_{\alpha}$ radiation $(1253.6 \mathrm{eV})$. The binding energies of core electrons were referred to $\mathrm{C} 1 \mathrm{~s}(285.0 \mathrm{eV})$.

\section{Results and Discussion}

\section{Autoreduction induced by axial coordination}

An excess of phosphine or phosphite was added to a chloroform solution of iron(III) chlorophyll $a$ to observe the axial coordination of the phosphorus ligand in solution. The reaction mixture was stirred at $30^{\circ} \mathrm{C}$ for $3 \mathrm{~h}$ under an argon atmosphere and the change in the electronic spectra was monitored spectrophotometrically. After the reaction mixture was cooled to $20^{\circ} \mathrm{C}$, the electronic spectrum was recorded and compared with that of the starting material (Fig. 2). As expected, both Soret and $\mathrm{Q}$ bands of the reaction mixture were red-shifted, i.e. shifted to longer wavelengths compared with those of the starting material. This red-shift in Soret and Q bands is an evidence for "autoreduction" which is induced by the axial co-

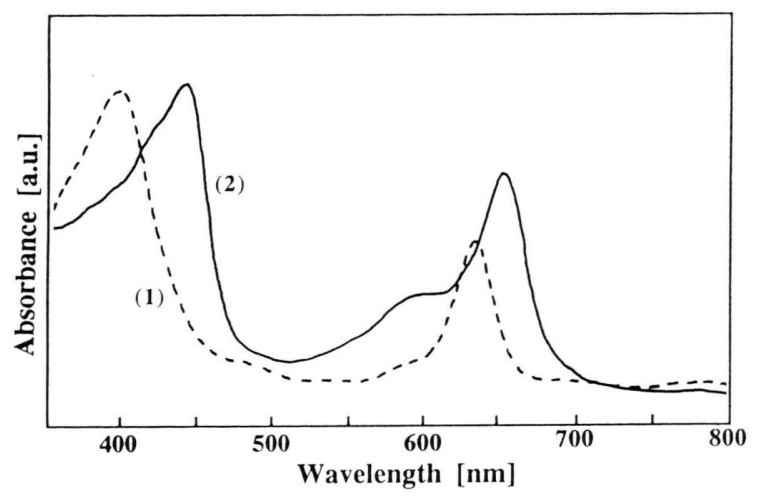

Fig. 2. Electronic spectra of (1) iron(III) chlorophyll $a$ and (2) its adduct with trimethylphosphine. 
ordination of phosphine or phosphite to iron(III) chlorophyll $a$. The axial coordination of phosphorus ligands $\left[\mathrm{PX}_{3}(\mathrm{X}=\right.$ alkyl or alkoxy group $\left.)\right]$ to iron(III) chlorophyll $a[\mathrm{Fe}(\mathrm{Chl}-a) \mathrm{Cl}]$ is expressed as follows:

$\mathrm{Fe}(\mathrm{Chl}-a) \mathrm{Cl}+\mathrm{PX}_{3} \rightarrow \mathrm{Fe}(\mathrm{Chl}-a)\left(\mathrm{PX}_{3}\right) \mathrm{Cl}$

$\mathrm{Fe}(\mathrm{Chl}-a)\left(\mathrm{PX}_{3}\right) \mathrm{Cl}+\mathrm{PX}_{3} \rightarrow\left[\mathrm{Fe}(\mathrm{Chl}-a)\left(\mathrm{PX}_{3}\right)_{2}\right]^{+} \mathrm{Cl}^{-}$

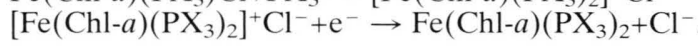

The third step, i.e. reaction (3), is called autoreduction. The bis-adduct of phosphine or phosphite with iron(III) chlorophyll $a$ is very rapidly formed at ambient temperature when an excess of the phosphorus ligands is used for reactions (1) and (2). The absorption maxima of the bis-adducts of iron chlorophyll $a$ are summarized in Table I. Soret and Q bands were red-shifted in all bis-adducts of phosphine or phosphite with iron chlorophyll $a$ and their red-shifts were $\sim 2580 \mathrm{~cm}^{-1}$ for Soret bands and $\sim 367 \mathrm{~cm}^{-1}$ for Q bands. The magnitude of the red-shift accompanied by the adduct formation is much the same for both phosphine and phosphite ligands. This indicates that the central iron(III) ion of iron(III) chlorophyll $a$ is reduced by the axial coordination of phosphine or phosphite at least under the present experimental conditions.

A toluene solution of iron(III) chlorophyll $a$ was spectrophotometrically titrated with phosphine or phosphite to observe more closely the axial coordination of the phosphorus ligand to the central iron(III) ion. A series of absorption spectra are reproduced for the reaction of iron(III) chlorophyll $a\left(1.0 \times 10^{-5} \mathrm{M}\right)$ with triethylphosphite in Fig. 3, where the concentration of triethylphosphite was varied from 0 to $6.93 \times 10^{-3} \mathrm{M}$. More

Table I. Absorption maxima $\left(\lambda_{\max }\right)$ of bis-adducts of a phosphine or phosphite with iron(III) chlorophyll $a$ at $25^{\circ} \mathrm{C}$.

\begin{tabular}{lll}
\hline Complex & \multicolumn{2}{c}{$\lambda_{\text {max }}(\mathrm{nm})$} \\
& Soret band & Q band \\
\hline $\mathrm{Fe}(\mathrm{Chl}-a) \mathrm{Cl}$ & 395 & 631 \\
$\mathrm{Fe}(\mathrm{Chl}-a) \mathrm{L}_{2}$ & & \\
$\mathrm{~L}: \mathrm{P}\left(\mathrm{CH}_{3}\right)_{3}$ & 439 & 649 \\
$\mathrm{P}\left(\mathrm{C}_{2} \mathrm{H}_{5}\right)_{3}$ & 441 & 651 \\
$\mathrm{P}\left(n-\mathrm{C}_{4} \mathrm{H}_{9}\right)_{3}$ & 440 & 646 \\
$\mathrm{P}(\mathrm{OCH})_{3}$ & 440 & 651 \\
$\mathrm{P}\left(\mathrm{OC} \mathrm{H}_{5}\right)_{3}$ & 440 & 646 \\
$\mathrm{P}\left(\mathrm{O}-n-\mathrm{C}_{4} \mathrm{H}_{9}\right)_{3}$ & 440 & 648 \\
\hline
\end{tabular}

than two isosbestic points were found from 350 to $800 \mathrm{~nm}$ during the course of the spectrophotometric titration. The entire equilibrium of the axial coordination is described by

$\mathrm{Fe}(\mathrm{Chl}-a) \mathrm{Cl}+2 \mathrm{PX}_{3} \rightarrow\left[\mathrm{Fe}(\mathrm{Chl}-a)\left(\mathrm{PX}_{3}\right)_{2}\right]^{+} \mathrm{Cl}^{-}$.

The Hill plots [10] were constructed for the reaction of iron(III) chlorophyll $a$ with triethylphosphite using the data of the spectrophotometric titration and illustrated together with the experimental conditions in Fig. 4. A similar type of Hill plot was also obtained for the adduct formation of iron(III) chlorophyll $a$ with phosphines or phosphites other than triethylphosphite. The slope of

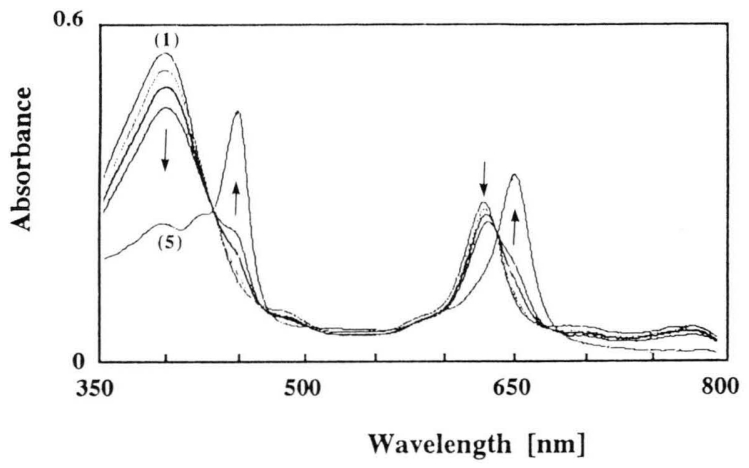

Fig. 3. Spectrophotometric titration of iron(III) chlorophyll $a$ with triethylphosphite. The concentration of iron(III) chlorophyll $a$ is $1.0 \times 10^{-5} \mathrm{M}$ and the concentrations of triethylphosphite are varied; (1) $0 \mathrm{M}$, (2) $2.97 \times 10^{-3} \mathrm{M}$, (3) $4.80 \times 10^{-3} \mathrm{M}$, (4) $6.51 \times 10^{-3} \mathrm{M}$ and (5) $6.93 \times 10^{-3} \mathrm{M}$.

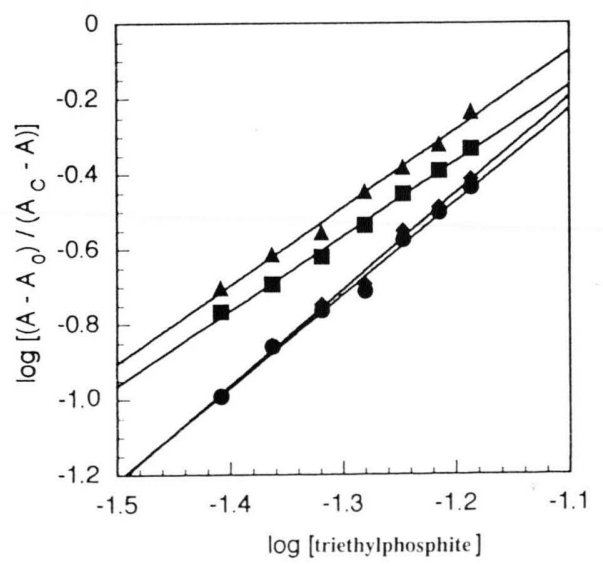

Fig. 4. Hill plots of $\log \left[\left(\mathrm{A}-\mathrm{A}_{0}\right) /\left(\mathrm{A}_{\mathrm{c}}-\mathrm{A}\right)\right]$ vs. $\log [$ triethylphosphite].

(ם) at $397 \mathrm{~nm} ;(\boldsymbol{\bullet})$ at $450 \mathrm{~nm} ;(\boldsymbol{\Delta})$ at $625 \mathrm{~nm}$; (•) at $652 \mathrm{~nm}$. 
the straight line was close to 2 in all cases, indicating that the reaction of iron(III) chlorophyll $a$ with phosphine or phosphite in toluene does not yield a mono-adduct, but a bis-adduct. This is consistent with the above interpretation that reactions (1) and (2) proceed very rapidly at ambient temperature. The equilibrium constant for reaction (4) was calculated from the intercept at $\log \left[\mathrm{PX}_{3}\right]=$ 0 of the Hill plots. For example, the equilibrium constant for $\mathrm{PX}_{3}=\mathrm{P}\left(\mathrm{C}_{2} \mathrm{H}_{5}\right)_{3}$ was $2.28 \times 10^{4} \mathrm{M}^{-2}$ at $25^{\circ} \mathrm{C}$, while that for $\mathrm{PX}_{3}=\mathrm{P}\left(\mathrm{OC}_{2} \mathrm{H}_{5}\right)_{3}$ was $2.49 \times 10^{2} \mathrm{M}^{-2}$ at $25^{\circ} \mathrm{C}$. In general the bis-adduct formation of the phosphine with iron(III) chlorophyll $a$ gave a larger equilibrium constant than that of the phosphite. This tendency is associated with the fact that the autoreduction of the central iron(III) ion of iron(III) chlorophyll $a$ occurs more easily in the bis-adduct of the phosphine than that of the phosphite.

\section{Spin states of intermediates in autoreduction}

The proton-decoupled ${ }^{31} \mathrm{P}$ NMR spectrum of the bis-adduct of iron chlorophyll $a$ with phosphine or phosphite was measured in the presence of excess phosphorus ligands. The singlet appeared downfield compared with that of the corresponding free ligand. The NMR data of the bis-adducts of iron chlorophyll a with phosphorus ligands are summarized in Table II in comparison with those on iron porphyrins. The NMR signal was observed in the range typical for low-spin iron(II) phosphine or phosphite complexes. In other words, the autoreduction of iron(III) chlorophyll $a$ is induced by the axial coordination of phosphine or phos-

Table II. ${ }^{31} \mathrm{P}-\mathrm{NMR}$ parameters of bis-adducts of a phosphine or phosphite with iron(II) chlorophyll $a$ and iron(II) porphyrins (in ppm).

\begin{tabular}{lccc}
\hline Ligand & $\delta($ Complex $)$ & $\delta$ (Ligand) & $\Delta \delta^{\mathrm{a}}$ \\
\hline $\mathrm{P}\left(\mathrm{CH}_{3}\right)_{3}$ & 11.2 & -61.7 & 72.9 \\
$\mathrm{P}\left(\mathrm{C}_{2} \mathrm{H}_{5}\right)_{3}$ & 53.5 & -19.7 & 73.2 \\
$\mathrm{P}\left(n-\mathrm{C}_{4} \mathrm{H}_{9}\right)_{3}$ & 58.5 & -30.7 & 89.2 \\
$\mathrm{P}\left(\mathrm{OCH}_{3}\right)_{3}$ & 189.8 & -141.6 & 48.2 \\
$\left.\mathrm{P}\left(\mathrm{OC}_{2} \mathrm{H}_{5}\right)_{3}\right)_{3}$ & 186.6 & -139.0 & 47.6 \\
$\mathrm{P}\left(\mathrm{O}-n-\mathrm{C}_{4} \mathrm{H}_{9}\right)_{3}$ & 186.8 & -139.4 & 47.4 \\
$\mathrm{Fe}(\mathrm{TPP})\left(\mathrm{P}\left(\mathrm{CH}_{3}\right)_{3}\right)_{2}{ }^{\mathrm{b}}$ & 10.8 & -60 & 70.8 \\
$\mathrm{Fe}(\mathrm{DPDME})\left(\mathrm{P}\left(\mathrm{CH}_{3}\right)_{3}\right)_{2}{ }^{\mathrm{b}}$ & 12.1 & -60 & 72.1 \\
\hline
\end{tabular}

a Coordination shift; $\Delta \delta=\delta$ (Complex) $-\delta$ (Ligand).

$\mathrm{b}$ taken from A. Bondon, P. Petrinko and G. Simonneaux, Biochim. Biophys. Acta 872, 163 (1986). phite to its central iron(III) ion. The coordination shift in the bis-adduct of iron chlorophyll $a$ with the phosphorus ligand is comparable to that in the corresponding bis-adduct of iron porphyrins. The coordination shift of the bis-adduct with phosphine is larger than that with phosphite. The drift of electrons from the phosphorus ligand atom to the central iron is large in the phosphine complex compared with the phosphite complex. The net drift of electrons is smaller in the phosphite complex due to the contribution of the Fe-to-P back donation than in the phosphine complex.

The ESR spectra of the reaction mixture of iron(III) chlorophyll $a$ with phosphine or phosphite were measured in a frozen solution of chloroform at $77 \mathrm{~K}$ to explore the spin state of the intermediates. The autoreduction was monitored directly in the ESR tube, generally with $2 \mathrm{ml} \mathrm{sam}$ ples of $10 \mathrm{mM}$ iron chlorophyll solutions containing a 10-100 molar excess of phosphorus ligands. A typical ESR spectrum of an adduct of iron(III)
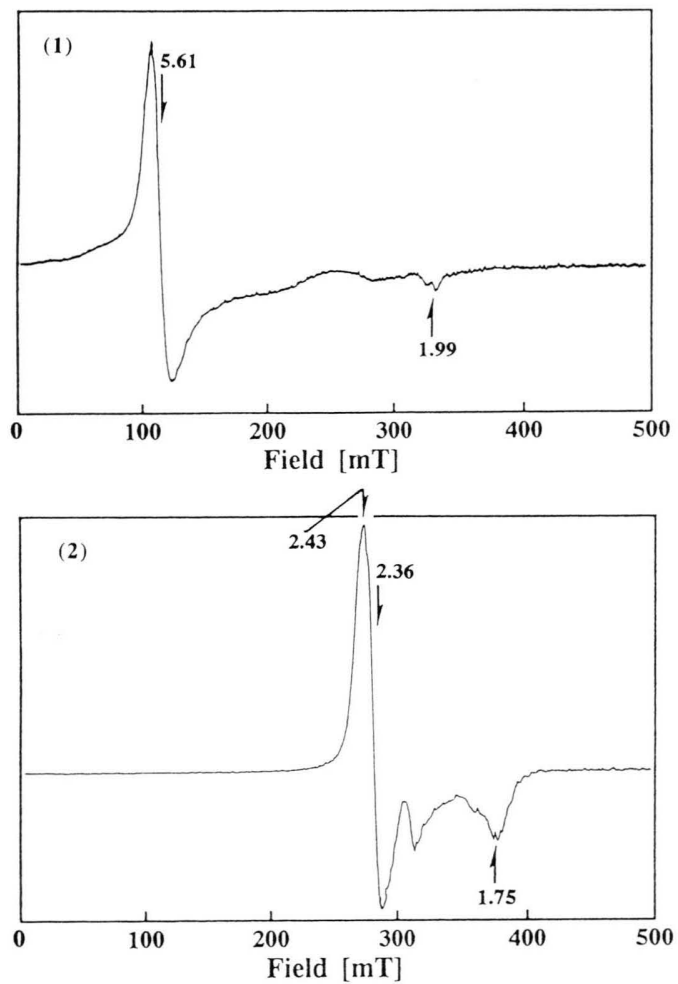

Fig. 5. ESR spectra of (1) iron(III) chlorophyll $a$ $\left([\mathrm{Fe}(\mathrm{Chl}-a) \mathrm{Cl}]=4.7 \times 10^{-3} \mathrm{M}\right)$ and $(2)$ its bis-adduct with trimethylphosphite $\left(\left[\mathrm{P}\left(\mathrm{OCH}_{3}\right)_{3}\right]=0.47 \mathrm{M}\right)$. 
Table III. ESR and ligand field parameters of bis-adducts of iron(III) chlorophyll $a$ and iron(III) tetraphenylporphyrin(TPP) with phosphites.

\begin{tabular}{lllllllllll}
\hline Ligand & $\mathrm{g}_{z}$ & $\mathrm{~g}_{y}$ & $\mathrm{~g}_{x}$ & $\mathbf{a}$ & $\mathbf{b}$ & $\mathbf{c}$ & $\mathbf{V} / \mathbf{l}$ & $\mathbf{D} / 1$ & $\left|\mathrm{~d}_{y z}-\mathrm{d}_{x y}\right|^{\mathrm{a}}\left|\mathrm{d}_{x z}-\mathrm{d}_{x y}\right|^{\mathrm{a}}$ \\
\hline $\mathrm{Fe}(\mathrm{Chl}-a) \mathrm{L}_{2}$ & & & & & & & & & & \\
$\mathrm{P}(\mathrm{OCH}$ & )$_{3}$ & 2.43 & 2.36 & 1.75 & 0.974 & 0.138 & 0.124 & 3.84 & 2.43 & 4.35 \\
$\mathrm{P}\left(\mathrm{OC}_{2} \mathrm{H}_{5}\right)_{3}$ & 2.43 & 2.35 & 1.80 & 0.980 & 0.129 & 0.113 & 4.11 & 2.72 & 4.78 & 0.51 \\
$\mathrm{P}\left(\mathrm{OC}_{4} \mathrm{H}_{9}\right)_{3}$ & 2.43 & 2.34 & 1.78 & 0.977 & 0.133 & 0.115 & 3.98 & 2.71 & 4.70 & 0.67 \\
$\mathrm{Fe}(\mathrm{TPP}) \mathrm{L}_{2}$ & & & & & & & & & & \\
$\mathrm{P}\left(\mathrm{OCH}_{3}\right)_{3}$ & 2.77 & 2.26 & 1.80 & 0.990 & 0.191 & 0.091 & 2.69 & 5.00 & 6.35 & 3.66 \\
$\mathrm{P}\left(\mathrm{OC}_{2} \mathrm{H}_{5}\right)_{3}$ & 2.76 & 2.28 & 1.78 & 0.984 & 0.191 & 0.098 & 2.69 & 4.51 & 5.85 & 3.16 \\
\hline
\end{tabular}

a The energy level separations were calculated as shown in Ref. [11] with a choice of sign and ordering as described in the text. The separations $\left|\mathrm{d}_{y z}-\mathrm{d}_{x y}\right|$ and $\left|\mathrm{d}_{x z}-\mathrm{d}_{x y}\right|$ are in units of 1 .

chlorophyll $a$ with trimethylphosphite is shown in Fig. 5 in comparison with that of the starting material, i.e. iron(III) chlorophyll $a$. During the course of the autoreduction of iron(III) chlorophyll $a$ by excess phosphorus ligands, a bis-adduct of low-spin iron(III) chlorophyll $a$ with trimethylphosphite, i.e. $\left[\mathrm{Fe}(\mathrm{Chl}-a)\left(\mathrm{P}\left(\mathrm{OCH}_{3}\right)_{3}\right)_{2}\right] \mathrm{Cl}$ is undoubtedly formed as an intermediate. The spin changes from $\mathrm{S}=5 / 2$ for $\mathrm{Fe}(\mathrm{Chl}-a)\left(\mathrm{PX}_{3}\right) \mathrm{Cl}$ to $\mathrm{S}=$ $1 / 2$ for $\left[\mathrm{Fe}(\mathrm{Chl}-a)\left(\mathrm{PX}_{3}\right)_{2}\right]^{+} \mathrm{Cl}^{-}$. It is noteworthy that the bis-adduct of low-spin iron(III) chlorophyll $a$, i.e. an intermediate was identified only for the phosphite complex under the present experimental conditions. The final product of the adduct formation of iron(III) chlorophyll $a$ with phosphine or phosphite was ESR inactive because the central iron(II) ion of the bis-adduct is in the lowspin state after autoreduction.

The energy separations of $d_{\pi}$ orbitals in $D_{4 h}$ symmetry can be calculated using the anisotropic g-values observed for the low-spin intermediate $\left[\mathrm{Fe}(\mathrm{Chl}-a)\left(\mathrm{PX}_{3}\right)_{3}\right] \mathrm{Cl}$ (where $\mathrm{PX}_{3}$ is phosphite). The notations of ESR parameters used for the present calculation are based on the formulas derived by Taylor [11]. The ESR parameters calculated are compared with those reported on $\left[\mathrm{Fe}(\mathrm{TPP})\left(\mathrm{PX}_{3}\right)_{2}\right] \mathrm{Cl}$ in Table III. It is of interest that the $\mathrm{d}_{\mathrm{xz}}$ and $\mathrm{d}_{\mathrm{yz}}$ orbitals are more stabilized in the bis-adducts of low-spin iron(III) chlorophyll $a$ than in those of low-spin iron(III) porphyrins. This relative lowering of the $\mathrm{d}_{\mathrm{xz}}$ and $\mathrm{d}_{\mathrm{yz}}$ orbitals in the bis-adduct of low-spin iron(III) chlorophyll $a$ is ascribed to the easy reduction of iron(III) chlorophyll $a$ compared with iron(III) porphyrins.

\section{Electronic structure of bis-adducts in solid state}

The bis-adducts of iron chlorophyll $a$ with phosphine or phosphite were carefully concentrated in the presence of excess phosphorus ligands. The residue obtained by careful evaporation of the
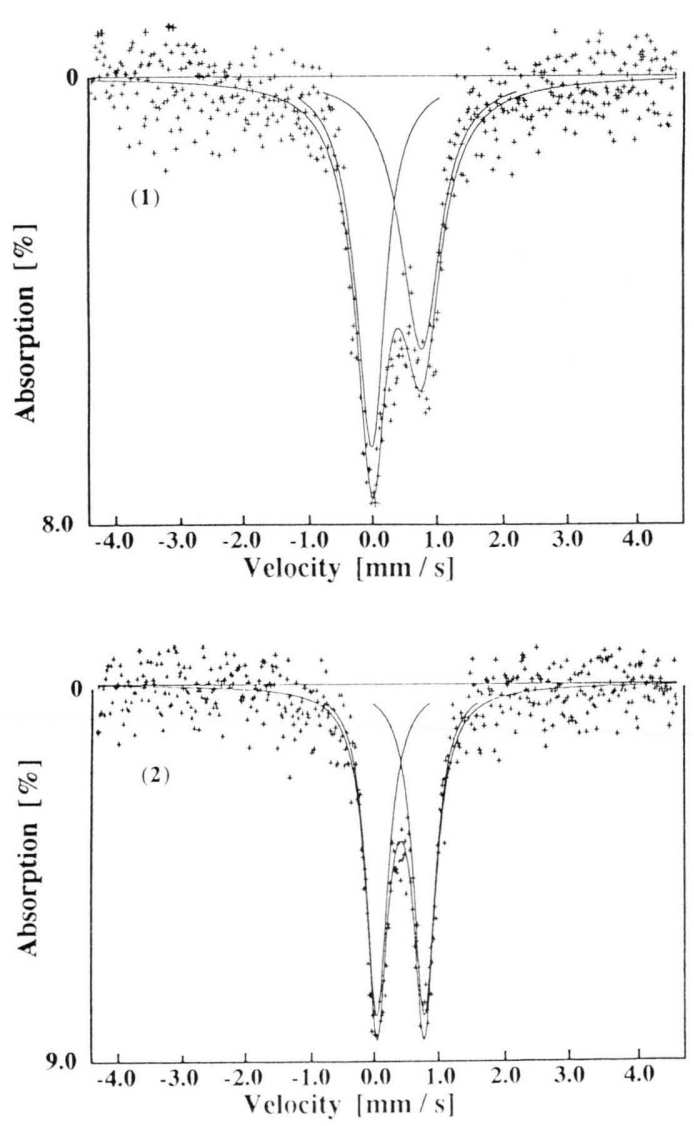

Fig. 6. Mössbauer spectra of (1) iron(III) chlorophyll $a$ and (2) its bis-adduct with trimethylphosphine. 
solvent of the reaction mixture was loaded into a polyethylene sample holder which was heat-sealed with partial cooling by liquid nitrogen. The typical ${ }^{57} \mathrm{Fe}$ Mössbauer spectra measured at $77 \mathrm{~K}$ are reproduced in Fig. 6. Iron(III) chlorophyll a, i.e. iron(III)(pheophytinato $a$ )chloride gave an asymmetric quadrupole-split doublet typical of a highspin five-coordinate iron(III) chlorine which is in a $\mathrm{d}^{5}$ configuration with a ${ }^{6} \mathrm{~A}$ ground state [12]. A dramatic change was observed on going from iron(III) chlorophyll $a$ to the corresponding bisadduct of phosphine or phosphite. The asymmetric quadrupole-split doublet became a symmetric one that is characteristic of low-spin iron(II) complexes. The Mössbauer parameters obtained for the adducts of iron chlorophyll $a$ with phosphine or phosphite are listed in Table IV in comparison with those of iron porphyrins. The Mössbauer parameters observed for the bis-adducts fall into the range typical for low-spin iron(II) porphyrins [13] and low-spin iron(II) chlorophylls [14]. This indicates that the central iron ion of the bis-adducts of iron chlorophylls with phosphine or phosphite is divalent and in the low-spin state. The isomer shifts of bis-adducts with phosphines increase in the order $\mathrm{P}\left(\mathrm{CH}_{3}\right)_{3}<\mathrm{P}\left(\mathrm{C}_{2} \mathrm{H}_{5}\right)_{3}<\mathrm{P}\left(\bar{n}-\mathrm{C}_{4} \mathrm{H}_{9}\right)_{3}$, while those of bis-adducts with phosphites decrease in the order $\mathrm{P}\left(\mathrm{OCH}_{3}\right)_{3}<\mathrm{P}\left(\mathrm{OC}_{2} \mathrm{H}_{5}\right)_{3}<$ $\mathrm{P}\left(\mathrm{O}-n-\mathrm{C}_{4} \mathrm{H}_{9}\right)_{3}$. The increasing tendency of the isomer shifts in the phosphine adducts is quite the reverse compared with that in the phosphite ad-

Table IV. Mössbauer parameters of bis-adducts of iron(II) chlorophyll $a$ and iron(II) porphyrin with a phosphine or phosphite at $77 \mathrm{~K}$.

\begin{tabular}{|c|c|c|}
\hline Ligand & $\begin{array}{l}\text { Isomer shift } \\
\delta\left(\mathrm{mms}^{-1}\right)\end{array}$ & $\begin{array}{l}\text { Quadrupole splitting } \\
\Delta \mathrm{E}_{\mathrm{Q}}\left(\mathrm{mms}^{-1}\right)\end{array}$ \\
\hline $\begin{array}{l}\mathrm{Fe}(\mathrm{Chl}-a) \mathrm{L}_{2} \\
\mathrm{P}\left(\mathrm{CH}_{3}\right)_{3} \\
\mathrm{P}\left(\mathrm{C}_{2} \mathrm{H}_{5}\right)_{3} \\
\mathrm{P}\left(n-\mathrm{C}_{4} \mathrm{H}_{9}\right)_{3}\end{array}$ & $\begin{array}{l}0.34 \\
0.37 \\
0.39\end{array}$ & $\begin{array}{l}0.77 \\
0.94 \\
1.14\end{array}$ \\
\hline $\begin{array}{l}\mathrm{P}\left(\mathrm{OCH}_{3}\right)_{3} \\
\mathrm{P}\left(\mathrm{OC}_{2} \mathrm{H}_{5}\right)_{3} \\
\mathrm{P}\left(\mathrm{O}-n-\mathrm{C}_{4} \mathrm{H}_{9}\right)_{3}\end{array}$ & $\begin{array}{l}0.34 \\
0.33 \\
0.32\end{array}$ & $\begin{array}{l}0.80 \\
0.80 \\
0.79\end{array}$ \\
\hline $\begin{array}{l}\mathrm{Fe}(\mathrm{TPP})_{\mathrm{L}_{2}}^{\mathrm{a}} \\
\mathrm{P}\left(\mathrm{C}_{2} \mathrm{H}_{5}\right)_{3} \\
\mathrm{P}\left(\mathrm{C}_{4} \mathrm{H}_{9}\right)_{3}\end{array}$ & $\begin{array}{l}0.38 \\
0.41\end{array}$ & $\begin{array}{l}0.78 \\
0.84\end{array}$ \\
\hline $\begin{array}{l}\mathrm{P}\left(\mathrm{OCH}_{3}\right)_{3} \\
\mathrm{P}\left(\mathrm{OC}_{2} \mathrm{H}_{5}\right)_{3}\end{array}$ & $\begin{array}{l}0.35 \\
0.36\end{array}$ & $\begin{array}{l}0.36 \\
0.38\end{array}$ \\
\hline
\end{tabular}

a Taken from Ref. [13].

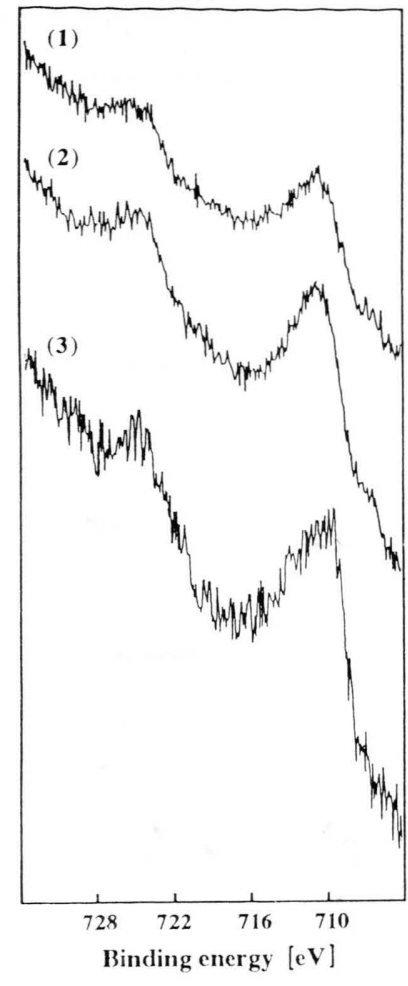

Fig. 7. X-Ray photoelectron spectra of (1) iron(III) chlorophyll $a$, (2) its bis-adduct with trimethylphosphine and (3) its bis-adduct with trimethylphosphite. ducts. On the other hand, the quadrupole splittings increase with the isomer shifts as a whole, when the quadrupole splittings are plotted against the isomer shifts. This tendency leads to the following interpretation about the $\mathrm{Fe}-\mathrm{P}$ bond in the bis-adducts of iron chlorophyll $a$ with phosphine or phosphite: The $\sigma$-donation from the phosphorus ligand atom to the central iron ion is predominant in the phosphine adducts. By contrast, the synergetic $\pi$-back donation from the filled $\mathrm{d}_{\pi}$-orbitals to the empty d-orbitals of the phosphorus ligand plays a certain role in the $\mathrm{Fe}-\mathrm{P}$ bond of the phosphite adducts.

The X-ray photoelectron spectra of the bis-adducts of iron chlorophyll $a$ with phosphine or phosphite were measured in solid state. The partial spectra in the energy region of the $\mathrm{Fe}_{2 \mathrm{p}}$ core electron level are shown in Fig. 7. The bis-adduct of low-spin iron(II) chlorophyll $a$ with phosphine or phosphite gave a slightly narrower $\mathrm{Fe} 2 \mathrm{p}_{3 / 2}$ peak than the parent compound, i.e. high-spin iron(III) chlorophyll $a$. The binding energies observed 
Table V. Binding energies of core electrons observed for bis-adducts of iron(II) chlorophyll $a$ and iron(II) porphyrins in $\mathrm{eV}$.

\begin{tabular}{lll}
\hline Compound & $\mathrm{N}_{1 \mathrm{~s}}$ & $\mathrm{Fe} 2 \mathrm{p}_{3 / 2}$ \\
\hline $\mathrm{Fe}(\mathrm{Chl}-a) \mathrm{Cl}$ & 399.1 & 710.0 \\
$\mathrm{Fe}(\mathrm{Chl}-a) \mathrm{L}_{2}$ & & \\
$\mathrm{~L}: \mathrm{P}\left(\mathrm{OCH}_{3}\right)_{3}$ & 399.1 & 709.8 \\
$\quad \mathrm{P}\left(\mathrm{CH}_{3}\right)_{3}$ & 398.8 & 708.3 \\
$\mathrm{Fe}(\mathrm{TFPP}) \mathrm{Cl}^{\mathrm{a}}$ & 397.3 & 709.5 \\
$\mathrm{Fe}(\mathrm{TFPP}) \mathrm{L}_{2}$ & 396.5 & 706.9 \\
$\mathrm{~L}: \mathrm{Im}$ & 396.5 & 706.9 \\
$\quad \mathrm{Py}$ & \\
\hline
\end{tabular}

a Taken from A. J. Signorelli, R. G. Hayes, J. Chem. Phys. 64, 4517 (1976). for the bis-adducts are summarized in Table $\mathrm{V}$ together with those reported on bis-adducts of iron(II) porphyrins. A comparison of these data reveals that the central iron ion of the bis-adduct of iron chlorophyll $a$ with phosphine or phosphite is divalent and in the low-spin state. This is consistent with the above conclusions drawn from the spectroscopic measurements other than X-ray photoelectron spectra.

\section{Acknowledgement}

The present work was partially supported by a Grant-in-Aid for Scientific Research No. 06453071 from the Japanese Ministry of Education, Science and Culture.
[1] L. M. Epstein, D. K. Straub, C. Maricondi, Inorg. Chem. 6, 1720 (1967).

[2] G. N. La Mar, J. Del Gaudio, Adv. Chem. Ser. 162, 207 (1977).

[3] J. Del Gaudio, G. N. La Mar, J. Am. Chem. Soc. 100, 1112 (1978)

[4] G. S. Srivatsa, D. T. Sawyer, Inorg. Chem. 24, 1732 (1985).

[5] C. E. Castro, M. Jamin, W. Yokoyama, R. Wade, J. Am. Chem. Soc. 108, 4179 (1986).

[6] H. Inoue, Y. Matsubayashi, T. Shirai, E. Fluck, Hyp. Inter. 29, 1403 (1986).

[7] K. Kadono, H. Hori, K. Fukuda, H. Inoue, T. Shirai, E. Fluck, Inorg. Chim. Acta 201, 213 (1992).
[8] M. O. Sege, K. M. Smith, Photochem. Photobiol. 54, 841 (1991).

[9] K. Furuya, H. Inoue, T. Shirai, Anal. Sci. 3, 353 (1987).

[10] F. A. Walker, Man-Wai Lo, T. M. Ree, J. Am. Chem. Soc. 98, 5552 (1976).

[11] C. P. S. Taylor, Biochim. Biophys. Acta 491, 137 (1977).

[12] H. Hori, K. Kadono, H. Inoue, T. Shirai, E. Fluck, J. Radioanal. Chem. Lett. 136, 159 (1989).

[13] T. Ohya, H. Morohoshi, M. Sato, Inorg. Chem. 23, 1303 (1984).

[14] H. Hori, K. Kadono, K. Fukuda, H. Inoue, T. Shirai, E. Fluck, Radiochim. Acta 49, 77 (1990). 